\title{
Mobile Devices: A Patent Need for Current Re-defining Education and Innovative Pedagogies
}

\author{
Akingbemisilu Abiola Afolabi
}

\begin{abstract}
The advent of mobile devices has done the world a lot of good, the ease of communicating any part of the world from the palms of one's hand has been a common phenomenon in the recent times globally. Almost all sectors of life has incorporated the use of these mobile devices for their operations. Education sector has joined this global dimension of using mobile devices for several of its activities. The extent of mobile devices usage for innovative pedagogy is quite uncertain. Though currently, Universities all over the world are making significant investments by incorporating technology systems to support various aspects of education with special focus on pedagogy. All their efforts are to make access to educational information on- the- go (mobile). Teachers and Students, on the other hand, are increasingly being equipped daily with mobile devices; most notably, mobile phones, laptop, tablets and i-pads which allow quick and easy communication and information sharing. These devices are emerging phenomenon of significance for innovative online pedagogy as they are majorly student-centred and they are mostly real time. Would the advent of these massive acquisitions of mobile devices by both the teachers and students really make any meaningful contribution to education in general and pedagogy in particular as anticipated by many scholars? This study therefore examines the availability, usage of mobile devices and the views of both university teachers and students in Ondo state, Nigeria on the need for mobile device for re-defining education and innovative pedagogy.
\end{abstract}

Index Terms-Innovative, mobile device, pedagogy, re-defining.

\section{INTRODUCTION}

Mobile devices, when well used for educational purposes would be a great lubricant in the wheel of educational progress. Generally, mobile equipment always come with such exceptional convenience and ease of use, it also often end the limitation of boundary and space. In recent times, Mobile devices ranging from mobile phones, tablets, i-pads, androids etc. have become more prevalent and affordable wireless technology. The constant and ever increasing demand for the use of mobile devices in our day to day life cannot be overemphasized. [1] said that in just the past few years, most of us have come to depend on mobile devices in our pockets. Even though hundreds of millions of people around the world now rely on mobile technology for many simple tasks, we are yet to tap its full potential to transform learning. Mobile technology could dramatically change the way education is delivered and improve educational outcomes.

Generally, students love mobile technology and use it regularly in their personal lives for communication, information sharing, and predominantly for social interaction. It is therefore no surprise that young people want to employ mobile devices to make education more engaging and personalize it for their particular needs says [2]. According to [3] the rapid advancement of emerging technology has increased the functionality of mobile communication devices in the contemporary world. In the recent time, mobile devices such as smart phones, tablets, i-pads cell phones and Personal Digital Assistant (PDAs) are built with functions that allow different applications, which enable connectivity and some other internet applications. Some of the functions of the cell phone can be equated with that of personal computer [2]. The additional features on these mobile devices and their capability to carry out function just like that of personal computer, has informed the rate of their use to grow rapidly among all ages everywhere in the world.

The prevalence of mobile devices ownership and its popularity, adoption and use among the present generation of students have attracted the attention of educators and researchers in information and communication technology. Educators all over the world, especially the educational technologists are exploiting these devices beyond mere utilizing them for communication only. Efforts are ongoing to investigate their use for teaching and implementing curriculum. The adoption of mobile device as a new learning tool is growing exponentially in the advance world. Its use for mobile learning is becoming a new development in e-learning and distance education. [4] considered mobile learning as an innovative way of utilizing handheld computer, internet-enabled cell phone for the delivery of instruction and learning content to students. [5] also opined that there is increase in the use of wireless technologies in education and that wireless technologies such as cell phone are transforming and changing educational landscape so much so that teaching and learning can take place anywhere, everywhere and anytime thereby creating a new innovation in learning process known as mobile learning.

"Reference [6] also pointed out the paradigm change in teaching and learning process with the use of mobile devices. There is therefore a concerted need to explore on the level of acceptance of mobile devices for re-defining education and to diagnose the potential and threats it might pose on the educational advancement of any nation.

\section{LITERATURE REVIEW}

Manuscript received November 29, 2014; revised February 28, 2015. Akingbemisilu Abiola Afolabi is with the Department of Science and Technical Education, Adekunle Ajasin University, Akungba-Akoko, Ondo State, Nigeria (e-mail: akingbemisilua@yahoo.com).

\section{A. Mobile Devices}


Any handy electronic machine that has input, processing, storage and output functionalities is considered a mobile device. The list is endless, ranging from calculators, smart phone, tablets, android, i -pad, computer notebook, laptop, ipod etc. [2] identified devices such as smart phones and tablets as powerful tools that would enable innovative teaching-learning process as well as to help students, teachers, and parents gain access to digital content and personalized assessment which is vital for a post-industrial world. Mobile devices, used in conjunction with near universal $4 \mathrm{G} / 3 \mathrm{G} / 2 \mathrm{G}$ wireless connectivity, are essential tools to improve learning for students. As noted by Irwin Jacobs, the founding chairman of Qualcomm, Inc., "always on, always connected mobile devices in the hands of students has the potential to dramatically improve educational outcomes." The challenges of space, distance, restriction to a point and access are easily surmounted using mobile devices. Mobile devices have unique features such as being handy, portable, transferable and easy to use.

Often, mobile devices are essential tools for communication and information sharing. They are used to perform almost all the functions of a typical Personal Computer (PC). There is the input compartment, processing compartment, storage compartment and output compartment in all mobile devices as it is obtainable in most $\mathrm{PC}$, therefore the use of mobile device is synonymous to that of a $\mathrm{PC}$ but with a unique attribute of mobility. According to [2], not every student have access to a computer and the Internet, and given the costs of hardware, it is often not affordable for school districts to provide a personal computer to every student but most young people today have phones, and mobile devices which when well harnessed would provide a real opportunity to transform instruction. [7] advocated for a more academic usage of these digital mobile devices that is always in the palms of students and teachers than its usage for social networking and communication purposes. All the personnel in education must embrace the use of mobile devices for innovative pedagogy.

\section{B. Incorporation of Mobile Devices for Current Redefining Education}

One of the current problems in education according to [2] is that teachers deal with classrooms of very diverse students and pupils come from different backgrounds, have divergent interests, and learn in unique ways. If we can take advantage of mobile devices and technology, it is possible to customize educational content for individual students.

Several studies has shown that students are more open to using technology for learning and that they are aware of these new learning tools such as text, illustration, audio and visual recordings, all of which provide students with a more holistic learning experience.

Studies have shown that students report positive impact on learning from digital technologies. Relying upon a mobile device in school furthermore help students. In the report of the Project Tomorrow survey on the use of mobile devices in schools, 73 percent of the participants in the survey said it helps them undertake research "anytime, anywhere", 63 percent raised the fact that they can receive reminders and alerts from these devices, 61 percent agreed that it aids in their collaboration with peers \& teachers, similarly, 54 percent credit it with organizing their schoolwork assignments, and 52 percent said mobile devices allow them to access their school network from home [2]. Considering the figures above, the incorporation of mobile devices for current education has really caused a great re-definition.

\section{Mobile Device for Innovative Pedagogies and Re-defining Education}

Innovative pedagogy involves the series of reports and forms explored in teaching, learning and assessment for an interactive world, which would guide teachers and policy makers in productive innovation. Mobile learning makes it possible to extend education beyond the physical confines of the classroom and beyond the fixed time periods of the school day. It allows students to access content from home, communicate with teachers, and work with other people online. The beauty of mobile devices when used for educational purpose is that it allows students to connect, communicate, collaborate and create quality educational contents using rich digital resources.

"Reference [7] identified "aiding learning" as an impact of digital mobile devices. He identified tablets in particular as useful for encouraging visual learning and for presenting information in dynamic ways to students with learning difficulties. [8] also corroborated that mobile digital tools enhance learning. They opined that human beings have become accustomed to living in a world of mediated expression that are created by combination of pictures, words and sounds which help viewers to significantly retain information longer than when they are only heard or read. Young people in particular are accustomed to personalized content and instantaneous communication. They seek information round the clock and pursue information that is relevant to their particular interests. Indeed, one of the virtues of mobile devices is their ability to provide personalized digital content 24/7.

Another benefit of the digital world for innovative pedagogy and redefining education is the precept on which mobile devices are based which is the ability to embed assessment within learning tools. Mobile devices enable detailed metrics on how students approach subjects, the process by which they acquire knowledge, and how quickly they pick up on key concepts and skills. When content is delivered in a mobile platform, it is easy to deploy pop-up quizzes that evaluate comprehension and knowledge thereby making teachers to be free from the mundane tasks of grading rote items and also help to provide immediate feedback for both students and parents. Other impacts of the mobile devises on education are that it can assist a teacher to develop dashboards that track classroom activities and individual student achievement on his or her learning curve. Students' academic progress can also be monitored by categorizing them into different groups based on whether they have fallen behind their peers and need remedial attention or whether they are on course with their fellow students, or have mastered current material and need more challenging assignments in order to advance their learning.

Flipped classroom, a current instructional strategy that is gaining attention in most part of the world according to [9] is 
now usually based on the use of mobile devices. Pre recorded lecture videos can be viewed by the students at home using their mobile phones, ipads or laptop and afterwards, come to the contact classroom for a collaborative session and for tackling assignment. [10] has described flipped learning as a success the world must embrace. If flipping a class which is predominantly dependent on mobile device usage is well applauded by many authors, the actual instrument that enables the success should be given better recognition. Thus, mobile device- a tool used for many recent excellent strategies and methods of instruction is actually redefining education and it's also making pedagogies to be very innovative.

\section{Methodology}

The research approach was chosen based on the research purpose and questions set to be answered. This study adopted mixed method approach, thus both qualitative and quantitative approach were used. Combining qualitative and quantitative approaches within the same piece of research ensures the overall effectiveness of the research process as one can enhance the findings of the other. Qualitative and quantitative data also help in revealing unanticipated results thus giving high confidence in the results obtained. This study adopted a case study strategy to explore how mobile devices could be a vital tool in current re-defining education and innovative pedagogy in tertiary institution. This helped to gain a rich understanding of the trend of mobile devices usage for educational purposes by both the university teachers (lecturers) and students. Questionnaire and semi structured interviews were used to collect data from respondents. The targeted populations for this study were lecturers and students in Ondo state government owned universities. A total of 300 respondents constituted the sample consisting of 250 students and 50 lecturers randomly selected from the three government owned universities in Ondo State, Nigeria.

\section{ANALYSIS AND DISCUSSION OF DATA}

Table I indicates that of all the students involved in this study, 248 (99.2\%) had mobile devices like phones, ipads or tablets and are with it always everywhere they go. Majority of them $201(80.4 \%)$ always use their mobile device for educational purpose, such as searching online and a significant part of the responding students $153(61.2 \%)$ do send/ share such information to/with their friends. 154 $(61.6 \%)$ of the sampled students can check their result on-line using the mobile device. $222(88 \%)$ of the sampled students were of the opinion that mobile device are needed for re-defining education and innovative pedagogy. As much as majority $189(75.6 \%)$ of the respondents believed that the procurement of mobile device is helping their education, they also considered it as a distracting tool when in the classroom for lessons. This result is consistent with the findings of [11], that mobile technologies not only provide a simple and accessible means for students to capture and send video images of key aspects of local fieldwork sites for immediate comment, they also prompt students on deadlines for required tasks as part of work placements, for example, completion of learning journals, portfolios, final presentations etc. From observation and interviews it came out that mobile device usage in educational activities help to facilitate timely and rapid feedback between academic teaching staff and students.

TABLE I: MOBILE Device USAGE By StUdents AND Their VIEWS ABOUT IT

\begin{tabular}{|lr|}
\hline Questions on Mobile devices & Frequency \\
\hline Possession of Mobile device like Phone, Ipad, laptop or tablet & $248(92 \%)$ \\
Use mobile device for educational purpose & $201(80.4 \%)$ \\
Use mobile device to share academic resources & $153(61.2 \%)$ \\
Use mobile device to check results and assignments online & $154(61.6 \%)$ \\
Participated in online class before using the mobile device & $99(39.6 \%)$ \\
Poised that mobile device is needed for re-defining education & $222(88.8 \%)$ \\
Poised that mobile device is a tool for innovative pedagogy & $221(88.4 \%)$ \\
Considered mobile device more suitable for education than other purposes & \\
& $150(60 \%)$ \\
& $51(20.4 \%)$ \\
Considered mobile device as a distraction during lesson & $189(75.6 \%)$ \\
\hline
\end{tabular}

TABLE II: MoBILE DEVICE USAGE By LeCTURERS AND THEIR VIEWS ABOUT IT

\begin{tabular}{|c|c|}
\hline Questions on Mobile devices & Frequency \\
\hline Possession of Mobile device like Phone, Ipad, laptop or tablet & $50(100 \%)$ \\
\hline Use mobile device for teaching activities & $45(90 \%)$ \\
\hline Encourages students to use their mobile device for educational purpose & $42(84 \%)$ \\
\hline Search for academic information using Mobile device & $49(98 \%)$ \\
\hline Shares academic information with colleagues using a mobile device & $48(96 \%)$ \\
\hline Consider mobile devices as a need for re-defining education & $49(98 \%)$ \\
\hline Students understand my lesson better whenever mobile devices are used & $44(88 \%)$ \\
\hline Do upload students' results and lesson note using mobile device & $45(90 \%)$ \\
\hline \multicolumn{2}{|l|}{ Have participated in an on-line conference/ class before using mobile device } \\
\hline & $11(22 \%)$ \\
\hline Consider mobile device as a tool for innovative pedagogy & $44(88 \%)$ \\
\hline Opined that mobile device serves as a distraction to students during lesson & $22(44 \%)$ \\
\hline \multicolumn{2}{|l|}{ Opined that the procurement and use of mobile device by both lecturers and } \\
\hline Students help education generally. & $41(82 \%)$ \\
\hline
\end{tabular}

The findings of this study equally agree with [11] in that mobile device helps to notify students of special events, 
media broadcasts etc. This study is also in line with the conclusion of [12] where they poised that cell phones and smart phones have been seen as increasingly useful educational tool in developing countries. [12] also argued that high mobile service penetration and increasing access to mobile phones have enabled some innovative projects that take advantage of "m-learning" or learning through mobile phones and that students can now download information to their phones, send and receive texts to and from their teachers, practice language and mathematical skills alone and with peers, and many other learning activities as also replicated and confirmed by this study.

Table II indicated that all the 50 sampled lecturers (100\%) have a mobile device, 49 of them (98\%) uses these mobile devices for searching academic information, they equally do share the searched academic information with their colleagues. 45 of them $(90 \%)$ do upload their results for the students to see, using their mobile devices. Also $45(90 \%)$ of them use their mobile devices for teaching activities. Majority of the lecturers $42(84 \%)$ do encourage their students to use their mobile devices for academic purposes. Almost all the sampled lecturers saw mobile device as a need for re-defining education and a tool for innovative pedagogy. 44 lecturers $(88 \%)$ poised that students understand better their lesson whenever mobile devices are used during instruction. However, majority 39(78\%)of the lecturers have not participated in any on-line conference/ class before using their mobile device. 41 lecturers $(82 \%)$ opined that the procurement and use of mobile device by both teachers and students is helping education generally, though 22 of the lecturers $(44 \%)$ considered mobile device as a distracting tool during lessons in classroom. This result is also in consonance with the submission of [13] as the readiness of teachers to use the new technologies is getting high despite many influencing variables that could have discourage the usage in developing countries. This study has exposed university lecturers as active users of mobile devices not only for communication purpose but also for educational and pedagogical purposes. Majority of the university lecturers now can upload their scores and lecture note on-line for students to see and read. It therefore implies that the massive acquisition of mobile devices is being warmly received by both students and lecturers for educational redefinition and pedagogical innovation.

\section{CONCLUSION}

At this juncture, it is clear that Mobile devices are being used by both students and lecturers for redefining education and innovative pedagogy. This study has demonstrated the progress being made in the inclusion of mobile device for serious educational activities as remarkable. Although [1] said that mobile technology potential has not been fully tapped to transform learning, several universities around the world are now using mobile technology to drive many of their educational activities and pedagogy in particular. The full potential of mobile technology will only be unlocked by effective use and re-use of these constantly inflowing mobile devices. There is the need for more institutions to join in the use of mobile technology for educational purposes. The possible constraints to effective usage of mobile device for instruction lies majorly with the teachers or/and the students. I established by this study that students can conveniently use mobile devices without any problem therefore to annex its usage for learning is considered a no problem for the students. Teachers, on the other hand who are the driver of any redefining education and innovative pedagogy must continue to sit up and face the challenge of using mobile devices for educational purpose. The question posed on whether the advent of these massive acquisitions of mobile devices by both the teachers and students really make any meaningful contribution to education in general and pedagogy in particular as anticipated by many scholars is hereby answered. There would be meaningful contribution to education if the mobile devices are well used as revealed in this study. This study can be replicated in other states of Nigeria to ascertain its findings. A parallel study involving polytechnics and colleges may also be carried out by prospective researchers to determine how the findings may agree or differ from that of a university as obtained in this study. Finally, researchers may choose a named mobile device and investigate how it could be used for re-defining education and innovative pedagogy.

\section{RECOMMENDATIONS}

What follows are some suggestions and comments regarding the use of mobile devices for educational activities. While the usage of mobile devices is rampant for social and communication purposes, efforts should be made by the Nigerian government through the federal ministry of education to introduce mobile education and encourage both teachers and students to use it. Lecturers need to be more involved in the usage of mobile devices. This way, they can influence and involve their students to the using of these same mobile devices for educational purposes. This will enhance understanding and achievement as students can access and read class lesson notes before the class. Also, students must convert the usage of mobile devices for academic purposes and not for entertainment or communication use only, as this will enrich their understanding in their subject matters.

\section{REFERENCES}

[1] V. Pandit, Transforming Learning through $m$-Education, McKinsey and Company, Mumbai, pp. 5-8, 2013.

[2] D. M. West, "Mobile learning: Transforming education, engaging Students, and improving outcomes," Brooke Shearers Working Paper Series, Publication for the Centre for Technology Innovation at Brooking, pp. 3-18, 2013.

[3] S. Lau, T. Law, and Parun, "Determinant of mobile acceptance for learning among students in developing country," The Malaysian Online Journal of Educational Technology, vol. 1, no. 3, pp. 3-13, 2010.

[4] A. Sife, E. Lwoga, and C. Sanga, "New technologies for teaching and learning: Challenges for higher learning institutions in developing countries," International Journal of Education and Development Using ICT, vol. 3, no. 2, pp. 21-35, 2007.

[5] T. H. Brown, "The role of m-learning in the future of e-learning in Africa higher education: pedagogies and technology," in Proc. the $21^{\text {st }}$ ICDE World Conference, Hong Kong, 2003, pp. 5-7.

[6] A. Barker, G. Krull, and B. Mallinson. (2010). A proposed theoretical model for m-learning adoption in developing countries. [Online]. Available: www.mlearn.org.za/CD/papers/Barker.pdf 
[7] A. A. Afolabi, "Effective digital tools for educational transformation in Nigeria: challenges, benefits and prospects," Journal of Educational Media and Technology, vol. 18, no. 1, pp. 61-66, Oct. 2014.

[8] S. A. Onasanya et al., "Influence of Satellite communication devices on students' acquisition of hidden curriculum in Nigeria Senior Secondary Schools," Journal of Education and Practice, vol. 3, no. 16 pp. 96-102, 2012.

[9] T. Greg. (2011). Flipped classroom take advantage of technology. USA TODAY. [Online]. Available: http://www.usatoday.com/news/education/story/2011-10-06/flipped-c lassrooms-virtual-teaching/50681482/

[10] B. Alvarez, "Flipping the classroom: Home work in class, lesson at home," Educational Digest: Essential Readings Condensed for Quick Review, vol. 77, no. 8, pp. 18-21, Aug. 2011.

[11] C. Armatas, D. Holt, and M. Rice, "From online enhanced to wholly online: Reflections on e-learning development in teaching psychology," in Proc. Content of ASCILITE, 2005.

[12] R. Winthrop and M. S. Smith, "A new face of education: Bringing technology into the classroom in the Developing world," Brooke Shearers Working Paper Series, Publication for the Centre for Technology Innovation at Brookings, pp. 7-11, 2012
[13] K. Redempta, "An e-learning approach to secondary School education: e-readiness implications in Kenya," Journal of Education and Practice, vol. 3, no. 16, pp. 142-147, 2012.

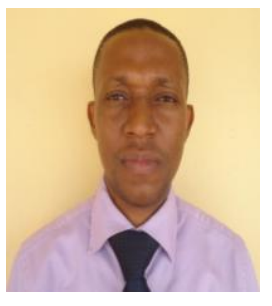

Akingbemisilu Abiola Afolabi is a doctora student in the Department of Teacher Education, University of Ibadan, Nigeria. He was born in Ondo, Ondo State Nigeria on December 7, 1979. He got his M.Ed. in educational technology in 2010 from University of Ibadan, and B.Sc.Ed. (Hons.) in biology in 2005 from Obafemi Awolowo University, Ile-Ife, and NCE biology/chemistry in 2001 from Adeyemi College of Education, Ondo.

He is currently a lecturer at Adekunle Ajasin University, Akungba-Akoko, Ondo State, Nigeria. He has published articles in many journals and books. His current research interest is in the area of use of various strategies of e-learning for effective lesson delivery.

Mr. Akingbemisilu is a registered member of Nigeria Association of Educational Media and Technology (NAEMT). 